\title{
Efficacy of Intravitreal Ranibizumab Injection in Acute Nonarteritic Ischemic Optic Neuropathy: A Long-Term Follow Up
}

\author{
Ali Osman Saatci ${ }^{*}, 1$, Okan Taskin ${ }^{1}$, Ozlem Barut Selver ${ }^{2}$, Aylin Yaman ${ }^{1}$ and Meltem Soylev Bajin ${ }^{1}$ \\ ${ }^{I}$ Department of Ophthalmology, Dokuz Eylul University, Izmir, Turkey \\ ${ }^{2}$ Department of Ophthalmology, Buca Seyfi Demirsoy State Hospital, Izmir, Turkey
}

\begin{abstract}
Background: To evaluate the effect of a single intravitreal ranibizumab injection in eyes with acute nonarteritic ischemic optic neuropathy (NAION).

Subjects and Methods: In this retrospective clinical data analysis, 17 eyes of sixteen patients who experienced a visual loss with duration of 15 days or less comprised the study group. In addition to standard ophthalmic examination, retinal nerve fiber layer thickness (RNFLT) analysis with spectral domain OCT was also performed prior to $0.5 \mathrm{mg}$ Ranibizumab injection, one week, one, three, six months and one year after the injection.

Results: The mean time between visual loss and intravitreal injection was 7.5 days (Range, 2-15 days). Mean age of patients was 59 years (Range, 41-90 years). Male to female ratio was 6:10. After a single dose of ranibizumab injection, visual gain was noted in 14 of 17 study eyes. In two eyes, visual acuity was minimally reduced and no change was noted in the remaining eye with an initial visual acuity of hand motions. While pre-injection mean best-corrected visual acuity (BCVA) was $1.45 \pm 0.88 \mathrm{log}$ Mar unit, post-injection mean BCVA was $1.00 \pm 0.68,0.86 \pm 0.70,0.80 \pm 0.71,0.77 \pm 0.70$, $0.77 \pm 0.70 \log$ Mar unit respectively at the first week, first month, third month, sixth month and first year. In all patients, the mean RNFLT dramatically decreased after the injection during the follow- up. While pre-injection mean RNFLT was $210 \pm 38 \mu \mathrm{m}$, post-injection mean RNFLT was $162.11 \pm 40.2,94 \pm 27,71.23 \pm 22.5,63 \pm 19$ and $57 \pm 18 \mu \mathrm{m}$ respectively at the first week, first month, third month, sixth month and first year. No injection related complication was noted during the follow-up period.

Conclusion: Intravitreal ranibizumab injection can be a treatment modality in eyes with acute NAION.
\end{abstract}

Keywords: Intravitreal injection, nonarteritic anterior ischemic optic neuropathy, optic coherence tomography, optic nerve, ranibizumab.

\section{INTRODUCTION}

Nonarteritic anterior ischemic optic neuropathy (NAION) is the most common optic neuropathy of the elderly that causes sudden visual loss [1]. Disease usually affects the patients over age of 50 and causes painless and unilateral visual loss. Fifteen $\%$ of patients with NAION developed the disease in the fellow eye within 5 years [2]. NAION is a multifactorial disease in which some systemic diseases may act as predisposing or precipitating factor including arterial hypertension, nocturnal arterial hypotension, diabetes mellitus, ischemic heart disease, cerebrovascular accidents and arteriosclerosis [3].

Today, there is still no well-established treatment for patients with NAION. Ischemic optic neuropathy decompression trial (IONDT) reported that spontaneous visual acuity improvement has been observed in $43 \%$ of

*Address correspondence to this author at the Mustafa Kemal Pasa Bulvari, No:73, A Blok, Daire: 9, Narlidere, Izmir, 35320, Turkey;

Fax: 90232 2782717; E-mail: osman.saatci@ deu.edu.tr

${ }^{\S}$ This study was presented in part at the ARVO meeting, Seattle, WA, USA May 5-9, 2013 patients within six months of disease onset [4]. In 2008, Hayreh \& Zimmerman [5] showed that early treatment of NAION with $80 \mathrm{mg}$ of oral prednisone therapy improved both the visual acuity and visual field in their nonrandomized-controlled study. Some researchers injected intravitreal triamcinolone acetonide instead of systemic steroids in order to to avoid systemic steroid side-effects [6,7]. However, intravitreal steroids have well-known steroidrelated ocular side effects, such as cataract progression and glaucoma. On the other hand, anti-vascular endothelial growth factor (VEGF) agents may be theoretically helpful as they reduce vascular permeability and thereby decrease optic nerve edema. Bennet et al. [8] were the first to perform intravitreal bevacizumab in a NAOIN patient. They reported a significant visual acuity gain and visual field improvement with rapid resolution of disc edema. Recently, including our pilot study, some researchers injected ranibizumab for the treatment of acute NAION and obtained some degree of functional and anatomic benefit [9-11].

In this study, we aimed to report the one-year result of $0.5 \mathrm{mg}$ intravitreal ranibizumab injection in 17 eyes of 16 patients with acute NAION. 


\section{SUBJECTS AND METHODS}

Clinical data of seventeen eyes of 16 consecutive patients with a visual loss history of 15 days or less were retrospectively evaluated. Diagnosis of NAION was based on the history of sudden visual loss, edematous optic disc appearance and characteristic visual field defects. Complete blood cell count, erythrocyte sedimentation rate and C-reactive protein analysis were obtained to exclude arteritic type of anterior ischemic optic neuropathy. Patients received a complete eye examination, including visual acuity testing, color vision evaluation with Ishihara's test, slit-lamp examination, Goldmann applanation tonometry, fundus examination, Humphrey's automated perimetry central (30-2 central threshold test) (Model 750 Humphrey Field Analyzer II, Carl Zeiss Meditec, Dublin, Calif., USA), and overall retinal nerve fiber layer thickness (RNFLT) analysis with Heidelberg Spectralis optical coherence tomography (OCT) (Spectralis HRA+OCT; Heidelberg Engineering, Heidelberg, Germany) prior to injection and at each visit. The natural disease course and various treatment options were discussed in detail with the patients and after obtaining the informed consent, $0.5 \mathrm{mg}$ Ranibizumab (Lucentis, Novartis Pharma Stein AG, Stein, Switzerland) was given intravitreally under topical anesthesia (Proparacaine Hydrochloride) $4 \mathrm{~mm}$ away from the limbus in phakic eyes and $3.5 \mathrm{~mm}$ away from the limbus in pseudophakic eyes in the operating room. All patients were re-examined at the first week, first, third and six months and first year after the injection. Statistical analysis was performed by using SPSS 15 program and Wilcoxon test.

\section{RESULTS}

The characteristics of patients and visual acuities are shown in the Table $\mathbf{1}$.

In our group, 6 patients had diabetes(37\%), 4 patients had hypertension (25\%), one patient had sleep-apnea syndrome.

After a single dose of ranibizumab injection, visual gain was reported in 14 of 17 eyes. In two eyes, visual acuity was minimally reduced and no change was noted in the remaining eye with an initial visual acuity of hand motions. While pre-injection mean best -corrected visual acuity (BCVA) was $1.45 \pm 0.88 \log$ Mar unit, post-injection mean BCVA was $1.00 \pm 0.68,0.86 \pm 0.70,0.80 \pm 0.71,0.77 \pm 0.70$, $0.77 \pm 0.70 \log$ Mar unit respectively at the first week, first month, third month, sixth month and first year. In all patients, the mean RNFLT dramatically decreased after the injection during the follow- up. While pre-injection mean RNFLT was $210 \pm 38 \mu \mathrm{m}$, post-injection mean RNFLT was $162.11 \pm 40.2,94 \pm 27,71.23 \pm 22.5,63 \pm 19$ and $57 \pm 18 \mu \mathrm{m}$ respectively at the first week, first month, third month, sixth month and first year.

Color vision and RNFLT changes are summarized in Table 2.

In Fig. (1) (Eye number 3) and Fig. (2) (eye number 8) the color fundus pictures, RNFLT analysis and visual field tests illustrate the kind of improvement patients experienced.

Visual fields improved in nine eyes and remained stable in eight eyes at the end of one year.

Table 1. Pre and Postinjection Visual Acuity Changes in the Study Group

\begin{tabular}{|c|c|c|c|c|c|c|c|c|}
\hline Eye No & Age/Sex/Eye & Time Between Visual Loss And Intravitreal Injection & Pre Injection & $\mathbf{1}^{\text {week }}$ & $1^{\text {month }}$ & $3^{\text {month }}$ & $6^{\text {month }}$ & $\mathbf{1}^{\text {year }}$ \\
\hline 1 & $62 / \mathrm{F} / \mathrm{L}$ & 2 days & 1,60 & 0,52 & 0,52 & 0,52 & 0,40 & 0,52 \\
\hline 2 & 90/M/L & 2 days & 1,60 & 1,30 & 1,30 & 1,30 & 1,0 & 1,0 \\
\hline $4^{*}$ & $51 / \mathrm{M} / \mathrm{R}$ & 3 days & 1,60 & 0,70 & 0,52 & 0,52 & 0,52 & 0,52 \\
\hline 5 & $45 / \mathrm{F} / \mathrm{R}$ & 4 days & 1,60 & 1,0 & 0,70 & 0,70 & 0,70 & 0,70 \\
\hline 6 & $61 / \mathrm{M} / \mathrm{L}$ & 6 days & 1,0 & 1,0 & 0,52 & 0,52 & 0,52 & 0,52 \\
\hline 7 & $52 / \mathrm{F} / \mathrm{R}$ & 7 days & 1,60 & 1,0 & 0,40 & 0,40 & 0,52 & 0,30 \\
\hline 11 & $54 / \mathrm{M} / \mathrm{R}$ & 9 days & 0,30 & 0,52 & 0,52 & 0,30 & 0,30 & 0,40 \\
\hline 12 & $61 / \mathrm{F} / \mathrm{L}$ & 10 days & 1,0 & 0,40 & 0,40 & 0,1 & 0,1 & 0,1 \\
\hline $13^{*}$ & $51 / \mathrm{M} / \mathrm{L}$ & 10 days & 3 & 1,60 & 1,60 & 1,60 & 1,60 & 1,60 \\
\hline 14 & 71/F/R & 11 days & 1,60 & 1,60 & 1,0 & 1,0 & 1,0 & 1,0 \\
\hline 15 & $55 / \mathrm{F} / \mathrm{L}$ & 11 days & 1,6 & 1,0 & 1,0 & 0,70 & 0,70 & 0,70 \\
\hline 16 & $64 / \mathrm{F} / \mathrm{L}$ & 12 days & 3 & 3 & 3 & 3 & 3 & 3 \\
\hline 17 & 41/F/R & 15 days & 1 & 0,70 & 0,70 & 0,70 & 0,70 & 0,70 \\
\hline
\end{tabular}


Table 2. Pre and Postinjection Color Vision and RNFLT Changes in the Study Group

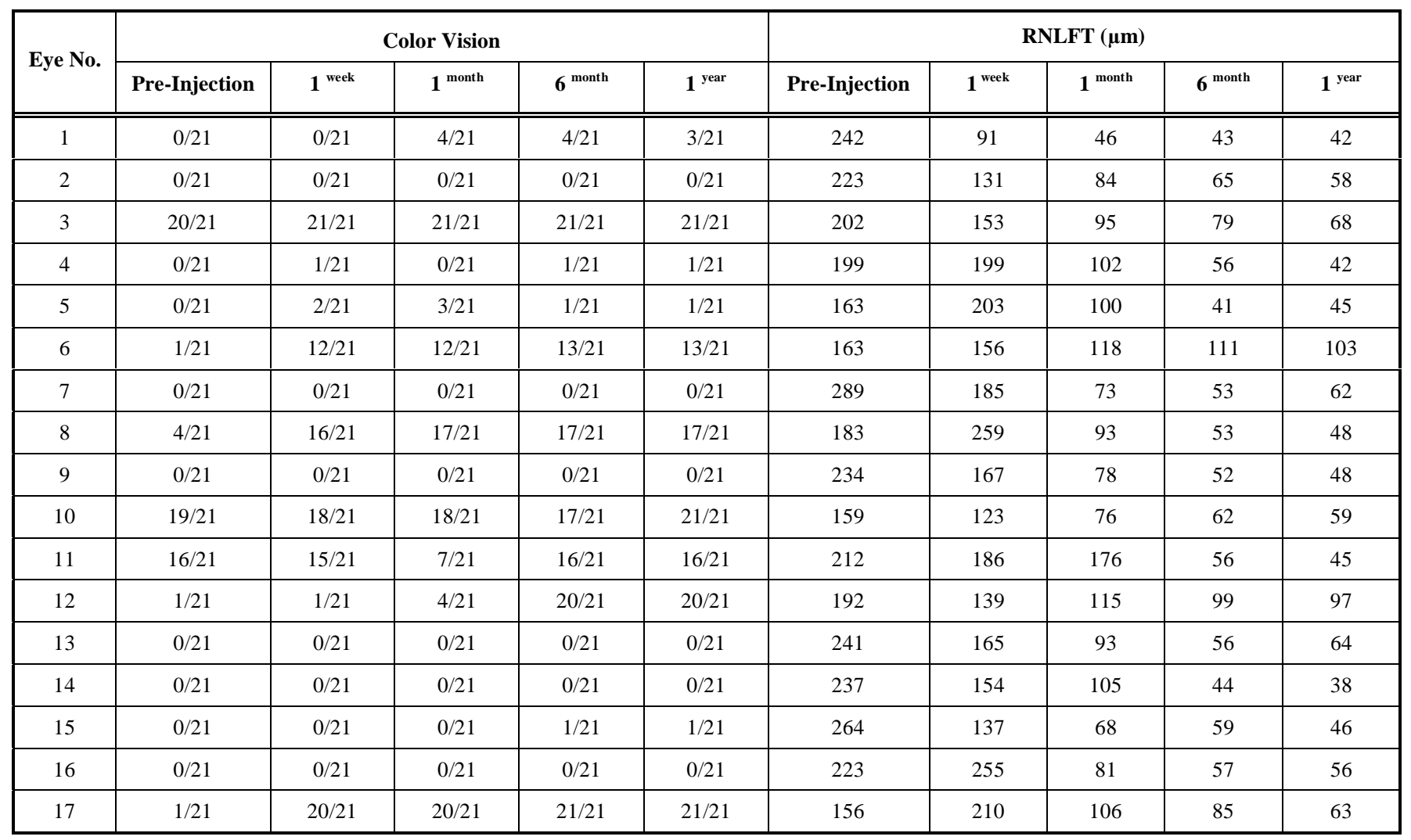

No injection related complication was noted during the follow-up period.

\section{DISCUSSION}

Although the exact mechanism and location of ischemia is still unclear, the small vessel circulatory disturbance of the optic nerve head is the likely scenario. The optic nerve head blood supply derives from an anastamotic arterial circle that originates from the short posterior ciliary arteries. Fluorescein angiographic studies demonstrated that the ischemia is the result of an insufficiency in the paraoptic branches of short posterior ciliary arteries [12].

The role of VEGF in NAION has not been established yet. Ischemia, which plays a role in the pathogenesis of ION, may likely to increase of VEGF and this may alter the vasopermeability and vasogenic edema of the optic nerve head. As the patients with a small cup to disk ratio are predisposed to NAION swelling may cause compression and infarction of the previously unaffected segments of the optic nerve head by creating a sort of compartment syndrome in a structurally crowded optic disc and result in apoptosis of retinal ganglion cells [13-16]. Treatment modalities are mostly empirical and encompass a wide range of agents presumed to act on thrombosis or on the disc edema itself [9]. As, vascular endothelial growth factor increases the vascular permeability besides stimulating angiogenesis, antiVEGF agents may have a potential to lessen optic disc edema $[17,18]$. Also a recent study reported that subretinal fluid was present in approximately $10 \%$ of NAION cases and this might contribute to visual loss. So employing anti-
VEGF agents may have a rationale in such patients to recover useful vision [18].

Bennet et al. [8] treated a 84 year-old woman with unilateral NAION of 3 weeks' duration with a single intravitreal $1.25 \mathrm{mg}$ bevacizumab injection. They demonstrated that optic nerve head edema reduced substantially and visual acuity improved. They also noted thinning of initially increased RNFLT with Stratus OCT 3. After this report, some authors published their experience with intravitreal bevacizumab injection in a small number of patients with acute NAION in a retrospective fashion [19,20]. Recently, Rootman et al. [20] compared the results of $1.25 \mathrm{mg}$ intravitreal bevacizumab injection with natural history of NAION in their non-randomized controlled clinical trial. Twenty-five patients were enrolled (17 eyes were treated and 8 eyes were served as control) in their study. They found no difference between the injection and control group regarding the change in visual field, visual acuity, or RNFL thickness. (measured with Cirrus OCT) Furthermore, two of their 17 treated eyes experienced a second NAION episode. The first was four days after the injection and the second was discovered outside of the study period.

There are only a few case series on the intravitreal ranibizumab injection for the treatment of acute NAION. Our preliminary report on four eyes treated with $0.5 \mathrm{mg}$ intravitreal ranibizumab, showed promising results after a follow-up of 3 months. All patients experienced visual gain [10]. Pece et al. [9] reported the results of three acute NAION cases who were treated with intravitreal ranibizumab injection. In all patients, they observed an early 

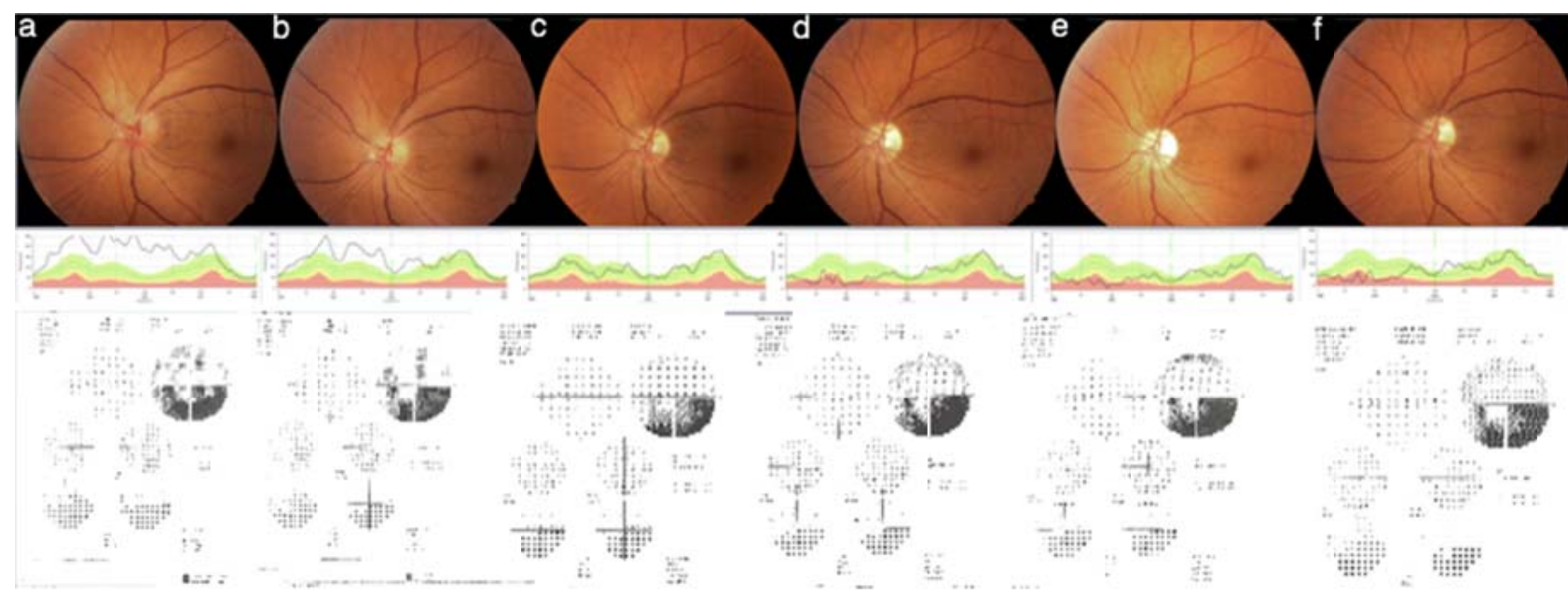

Fig. (1). Eye number 3, color fundus picture, retinal nerve fiber layer thickness evaluation and visual field test obtained at preinjection (a), one week (b), one month (c), three months (d), six months (e) and one year (f) after the injection.
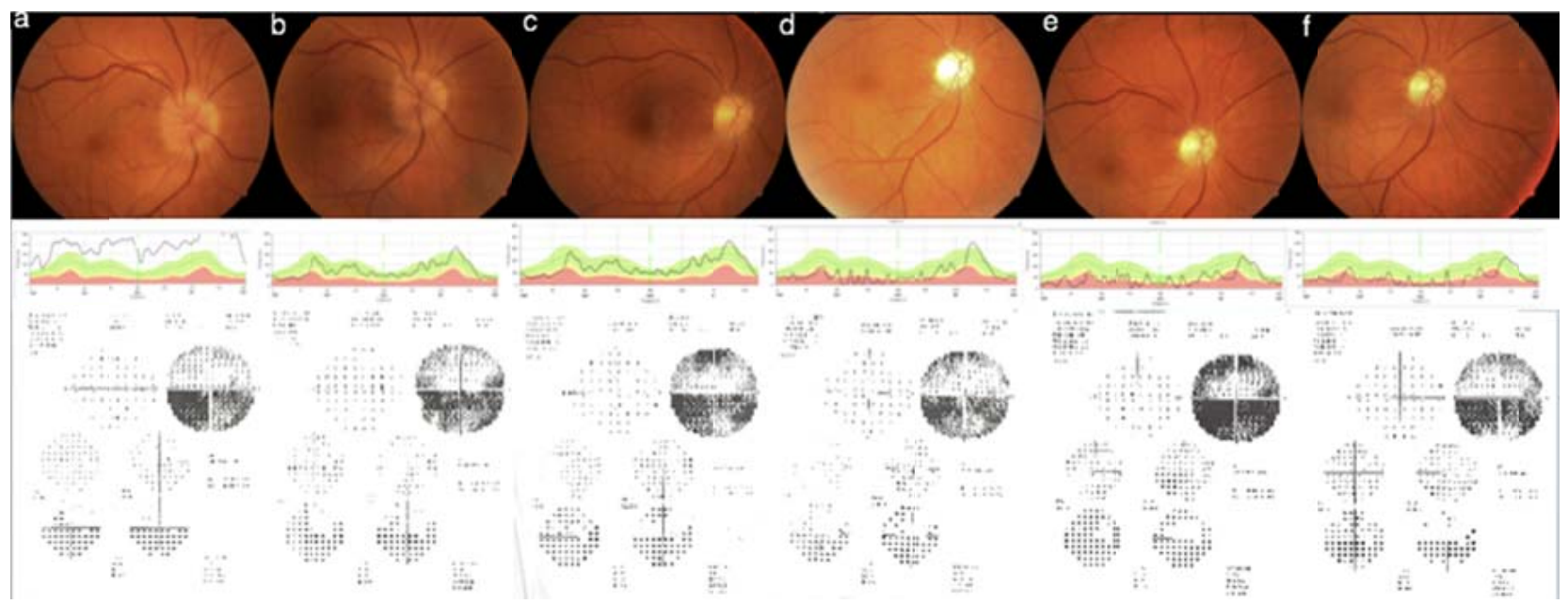

Fig. (2). Eye number 8, color fundus picture, retinal nerve fiber layer thickness evaluation and visual field test obtained at preinjection (a), one week (b), one month (c), three months (d), six months (e) and one year (f) after the injection.

resolution of optic disk swelling noted immediately after the first week of injection however visual acuity and perimetric improvement did not accompany. Samant et al. [11] evaluated the effect of single intravitreal ranibizumab injection in six acute NAION patients. They performed the injection within the fifteen days of presentation and all six patients experienced visual improvement one week after the injection. Spectral domain OCT demonstrated a reduction in peripapillary thickness by an average of $230 \mu \mathrm{m}$ at one month.

An unanswered question was whether the time lapse between the episode and anti-VEGF agent injection mattered or not? Natural history data shows that visual acuity may worsen progressively over 2 weeks and then become stable [13]. Animal studies suggest that the therapeutic window for acute NAION may be as long as 2 to 3 weeks [18]. Visual dysfunction appears to reach a plateau around the time that optic disk edema is decreased and optic atrophy ensues [21]. Hayreh \& Zimmerman [5] indicated a two-week therapeutic window for the employement of systemic steroids. Based on these informations, we elected to perform the intravitreal injection at maximum 15 days after the onset of the disease.

Another controversial aspect of intravitreal anti -VEGF agents in the treatment of acute NAION is the possible role of anti-VEGF agents by themselves on inducing or facilitating acute NAION [22-25]. In one of these reports, a patient who had a small cupless disc experienced an episode of NAION two weeks after the injection of bevacizumab [24]. In a second report, an episode of NAION was noted in a patient with diabetic macular edema three weeks after the bevacizumab injection [23]. These findings may be coincidental or related to anti-VEGF activity. Mansour et al. [25] suggested that potential mechanisms include the vasoconstrictor effect of the anti-VEGF agents, an increase in intraocular pressure from the intravitreal injection and the exacerbation of systemic hypertension from the stress of the procedure. As ranibizumab has a shorter vitreous half-life than bevacizumab (2.88 days versus 4.32) [26-28] it can be speculated that ranibizumab can be a better choice over 
bevacizumab in eyes with acute NAION if an anti-VEGF agent will be injected.

The possibility of spontaneous recovery during the natural course of acute NAION does not enable us to attribute high percentage of the visual gain in our study eyes to intravitreal ranibizumab injection. Though spontaneous visual acuity improvement has been observed in $43 \%$ of patients within six months of disease onset in ischemic optic neuropathy decompression trial (IONDT) no visual improvement was seen in $45 \%$ of patients and even further visual decline was noted in $12 \%$ of the cases. ${ }^{4}$ So it can be only speculated that intravitreal ranibizumab injection might have altered the natural disease course positively and helped us to achieve a better visual outcome in our study population. However, we did not have a control group. When the disease course was explained in detail, none of our patients agreed to stay without any treatment.

A randomized controlled study in a larger group of patients is necessary to reach a more reliable conclusion. In light of our study, we feel that intravitreal ranibizumab injection may be offered to patients with acute NAION.

\section{CONFLICT OF INTEREST}

The authors confirm that this article content has no conflict of interest.

\section{ACKNOWLEDGEMENTS}

Declared none.

\section{REFERENCES}

[1] Hayreh SS. Anterior ischemic optic neuropathy I. Terminology and pathogenesis. Br J Ophthalmol 1974; 58: 955-63.

[2] Newman N, Scherer R, Kelman S, et al. The fellow eye in NAION: report from the ischemic optic neuropathy decompression trial follow-up study. Am J Ophthalmol 2002; 134: 317-28.

[3] Hayreh SS, Joos KM, Podhajsky PA, Long CR. Systemic disease associated with nonarteritic ischemic optic neuropathy. Am J Ophthalmol 1994; 118: 766-80.

[4] Ischemic Optic Neuropathy Decompression Trial Research Group. Optic nerve decompression surgery for the nonarteritic anterior ischemic optic neuropathy (NAION) is not effective and may be harmful. JAMA 1995; 273: 625-32.

[5] Hayreh SS, Zimmerman MB. Non-arteritic anterior ischemic optic neuropathy: role of systemic corticosteroid therapy. Graefes Arch Clin Exp Ophthalmol 2008; 246: 1029-46

[6] Kaderli B, Avci R, Yucel A, et al. Intravitreal triamcinolone improves recovery of visual acuity in nonarteritic anterior ischemic optic neuropathy. J Neuro-ophthalmol 2007; 27: 164-8.

[7] Yaman A, Selver OB, Saatci AO, et al. Intravitreal triamcinolone acetonide injection for acute non-arteritic anterior ischemic optic neuropathy. Clin Exp Optom 2008; 91: 561-4.
[8] Bennett JL, Thomas S, Olson JL, et al. Treatment of nonarteritic anterior ischemic optic neuropathy with intravitreal bevacizumab. J Neuro-ophthalmol 2007; 27: 238-40.

[9] Pece A, Querques G, Quinto A, Isola V. Intravitreal ranibizumab injection for nonarteritic ischemic optic neuropathy. J Ocul Pharmacol Ther 2010; 26: 523-7.

[10] Bajin MS, Selver OB, Taskin O, Yaman A, Saatci AO. Single intravitreal ranibizumab injection in eyes with acute non-arteritic anterior ischaemic optic neuropathy. Clin Exp Optom 2011; 94 367-70.

[11] Samant PM, Samant HP, SaraiyaKA. Single intravitreal ranibizumab injection in eyes with acute non-arteritic anterior ischemic optic neuropathy. J Clin Ophthalmol Res 2013;1: 27-8.

[12] Arnold AC. Pathogenesis of nonarteritic anterior ischemic optic neuropathy J Neuro-Ophthalmol 2003; 23: 157-63.

[13] Atkins EJ, Bruce BB, Newman NJ, Biousse V. Treatment of nonarteritic anterior ischemic optic neuropathy. Surv Ophthalmol 2010; 55: 47-63.

[14] Levin LA, Louhab A. Apoptosis of retinal ganglion cells in anterior ischemic optic neuropathy. Arch Ophthalmol 1996; 114: 488-91.

[15] Arnold AC. Pathogenesis of nonarteritic anterior ischemic optic neuropathy J Neuro-Ophthalmol 2003; 23: 157-63.

[16] Hayreh SS, Zimmerman MB. Optic disc edema in non-arteritic anterior ischemic optic neuropathy Graefes. Arch Clin Exp Ophthalmol 2007; 245: 1107-21.

[17] Slater BJ, Mehrabian Z, Guo Y, et al. Rodent anterior ischemic optic neuropathy (rAION) induces regional retinal ganglion cell apoptosis with a unique temporal pattern. Invest Ophthalmol Vis Sci 2008; 49: 3671-76

[18] Hedges TR, Vuong LN, Gonzalez-Garcia AO, et al. Subretinal fluid from anterior ischemic optic neuropathy demonstrated by optical coherence tomography. Arch Ophthalmol 2008; 126: 812-5.

[19] Prescott CR, Sklar CA, Lesser RL, Adelman RA. Is intravitreal bevacizumab an effective treatment option for nonarteritic anterior ischemic optic neuropathy? J Neuroophthalmol 2012; 32: 51-3.

[20] Rootman DB, Gill HS, Margolin EA. Intravitreal bevacizumab for the treatment of nonarteritic anterior ischemic optic neuropathy: a prospective trial. Eye 2013; 27: 538-544.

[21] Hayreh MB. Zimmerman Optic disc edema in non-arteritic anterior ischemic optic neuropathy Graefes Arch Clin Exp Ophthalmol 2007; 245: 1107-21.

[22] Gordon-Angelozzi M, Velez-Montoya R, Fromow-Guerra J, et al. Bevacizumab local complications. Ophthalmology 2009; 116: 2264

[23] Huang JY, Ozaki H, Hayashi H, Uchio E. Anterior ischemic optic neuropathy following intravitreal bevacizumab. Jpn J Ophthalmol 2010; 54: 252-4.

[24] Bodla AA, Rao P. Non-arteritic ischemic optic neuropathy followed by intravitreal bevacizumab injection: is there an association? Indian J Ophthalmol 2010; 58: 349-50.

[25] Mansour AM, Schwartz SG, Gregori NZ, et al. Insight into 8 patients with nonarteritic anterior ischemic optic neuropathy following anti-VEGF injections. J Neuroophthalmol 2012; 32(2): 193.

[26] Ratner M. Genentech discloses safety concerns over Avastin. Nat Biotechnol 2004; 22: 1198

[27] Zou L, Lai H, Zhou Q, Xiao F. Lasting controversy on ranibizumab and bevacizumab. Theranostics 2001; 1: 395-402.

[28] Bakri SJ, Snyder MR, Reid JM, Pulido JS, Ezzat MK, Singh RJ. Pharmacokinetics of intravitreal ranibizumab (Lucentis). Ophthalmology 2007; 114: 2179-82.

This is an open access article licensed under the terms of the Creative Commons Attribution Non-Commercial License (http://creativecommons.org/licenses/by$\mathrm{nc} / 3.0 /$ ) which permits unrestricted, non-commercial use, distribution and reproduction in any medium, provided the work is properly cited. 